\title{
EDITORIAL - PENSAMENTO MARXIANO: BREVES PALAVRAS SOBRE LUTA IDEOLÓGICA, DETERMINAÇÃO ECONÔMICA E AMÉRICA LATINA
}

\author{
Deise Luiza Ferraz ${ }^{1}$
}

Como responsável pela última edição da Revista Brasileira de Estudos Organizacionais de 2015, tomo a liberdade de alongar-me um pouco em um prólogo à apresentação dos textos que este número nos traz, isso porque não seria possível deixar passar um fato que ocorreu recentemente e demonstrou o movimento de consolidação e amadurecimento da Sociedade Brasileira de Estudos Organizacionais, doravante, Sociedade. O farei, porém, sem perder de vista a abordagem teórica dos textos apresentados: a teoria marxiana, sobretudo, porque essa abordagem não está destoante do fato que assinalarei nos parágrafos finais deste texto.

O Terceiro Congresso Brasileiro de Estudos Organizacionais, realizado em outubro deste ano na Universidade Federal do Espírito Santo (UFES) antes dos minérios da Samarco tingir o mar desse estado, diga-se de passagem, brindou a Sociedade com o estabelecimento de relações internacionais, conforme cartilha da Capes, mas um tanto quanto à revelia dessa, porque a Sociedade ousou em não resumir o vocábulo internacional aos países de língua anglo-francófona "centrais".

O acordo firmado com a Red de Posgrados e Investigación Latinos en Administración y Estudios Organizacionales - (RED PILARES) e com a Red Mexicana de Investigadores en Estudios Organizacionales (REMINEO) permite aos intelectuais brasileiros o impulso que faltava para olharmos para a América Latina. Esforços nessa linha vêm sendo realizados por diversos grupos de pesquisa no país - não os nomeio para não correr o risco do esquecimento de algum, mas é necessário registrar: o acordo não resulta de uma vontade imediatista ou de um casualismo oportuno, trata-se da institucionalização que resulta do trabalho de pesquisadores latinoamericanos, creio não ser necessário assinalar, porém, deixo o registro, latino-americano inclui a academia brasileira.

A história do desenvolvimento econômico, político, cultural2 do Brasil não pode ser compreendido apartado da história dos países do nosso continente. Há suas particularidades, não se questiona isso, porém, no

\footnotetext{
${ }^{1}$ Doutora e Mestra em Administração pela EA/UFRGS, Professora e Pesquisadora do CEPEAD/FACE/UFMG. Coordenadora do Núcleo de Estudos Críticos Trabalho e Marxismo.

2 O termo cultural é aqui utilizado na perspectiva marxiana de cultura, trata-se, portanto, de uma visão totalizadora - o que é diferente de total - dos elementos objetivos e subjetivos que constituem o que a sociedade está sendo, do que decorre que a História é a história da cultura.

Revista Brasileira de Estudos Organizacionais • v.2. n. 2, p. 134-138, dez.2015, eISSN: 2447-4851 Sociedade Brasileira de Estudos Organizacionais
} 


\section{EDITORIAL - PENSAMENTO MARXIANO: BREVES PALAVRAS SOBRE LUTA IDEOLÓGICA, DETERMINAÇÃO ECONÔMICA E AMÉRICA LATINA

movimento de totalização, múltiplos são os elementos comuns que permitem compreender a expansão ${ }^{3}$ do capital nas Américas, particularmente, sobre a parte latina. Expansão que está operando um novo avanço ofensivo, de um modo geral, por meio da esfera política, cujos sinais estamos observando com maior intensidade na Argentina, no Brasil, na Venezuela. Trata-se do desdobramento de vários fatores, dos quais destacam-se a crise econômica mundial e a prática política específica de cada Estado.

O capital, para expandir-se, move-se de múltiplas formas, não entrarei no quesito da necessidade dos câmbios de governo para agilizar a "expansão interna". Destaco que a "expansão externa" que o capital está fazendo em Cuba é um exemplo de como o que tem ocorrido na América Latina, embora com particularidades, está interconectado e que, portanto, a alteração dos nossos horizontes oportunizada pelo acordo firmado pelas Sociedades supracitadas resulta da própria realidade que compartilhamos e que temos discutido, ainda que pouco.

Antes de prosseguir, destaco que esse editorial está, como não poderia deixar de ser, influenciado pelas discussões que tenho presenciado nos últimos dias no Instituto de Filosofia de Cuba, especificamente, na Jornada Científica "De Marx a Fidel Castro: La relación Económia, Moral y Política en la práxis revolucionaria" realizada pela Cátedra de Estudios Marxistas Julio Antonio Mella, coordenado pela Doutora Isabel Monal.

Transformações estão ocorrendo na Ilha desde a década de 1990, "por que agora os EUA querem reestabelecer relações com Cuba?". Se os intelectuais cubanos estão discutindo as múltiplas e complexas respostas a essa pergunta, não seria em um editorial que dar-se-ia a resposta, porém como o intuito de mostrar os traços fortes que nos são comum, importante destacar cinco elementos essenciais que atraem os investimentos em forma de Capital para a Ilha, quais sejam: 1) uma população jovem, a despeito do processo de envelhecimento da sociedade cubana, com saúde e letrada - e o mais contraditório, essa reserva de força de trabalho não "custou nada ao Capital"; 2) um solo muito fértil para a agricultura, sem falar em sua biodiversidade; 3) dois quesitos importantes para o turismo: as belezas naturais e uma história ímpar de resistência; 4) uma demanda reprimida por diversos tipos de mercadorias, sobretudo os provenientes da tecnologia - muitos daqueles jovens saudáveis e possuidores de conhecimento técnico em várias áreas estão dispostos a adquirir; e, 5) sua posição geográfica. Algumas coincidências com o avanço do capital no Brasil após sua democratização podem ser vistas?

\footnotetext{
${ }^{3}$ Expansão do capital, como destaca Marx em Gundrisse, ocorre em dois sentidos. Resumidamente: o capital se expande para regiões onde não é o modelo (hegemônico) de produção e, onde já o é, expande-se avançando na especialização de produção de valores de uso em setores que se desenvolveram pela capacidade inerente do trabalho humano de, ao mesmo tempo em que transforma o meio para satisfazer as necessidades existentes, produz novas necessidades. Porém, cabe lembrar que: sob o sistema de capital essa criação de novos valores de uso está subsumida a condição sine qua non da produção de valores de troca e mais valor. Ademais, sendo o sistema do capital, um sistema metabólico, com seu desenvolvimento ele produz seus próprios pressuposto.
} 


\section{EDITORIAL - PENSAMENTO MARXIANO: BREVES PALAVRAS SOBRE LUTA IDEOLÓGICA, DETERMINAÇÃO ECONÔMICA E AMÉRICA LATINA \\ Deise Luiza Ferraz}

Esses pontos não foram discutidos na referida Jornada, não apenas porque esses elementos são compreendidos como a forma particular de manifestação dos fatores universais demandados pelo capital para expandir-se, mas porque a realidade impõe aos intelectuais cubanos perguntas que urgem respostas, tendo o centro das discussões versado sobre: "Como manter o movimento de transição socialista 4 frente às mudanças?" ou, em outras palavras, como regular politicamente a expansão do capital (para não retroceder nos avanços da transição)? Embora Mészáros ${ }^{5}$ tenha atentado, a partir de Marx, para a incontrolabilidade do sociomentabolismo do capital, são as tentativas de contê-lo que produzem sujeitos históricos capazes de construírem as transformações necessárias para o devir da emancipação humana, caso não fosse assim, reinaria o determinismo finalístico e negar-se-ía, justamente, aquilo que nos torna humano: nossa capacidade de pores teleológico (LUKÁCS, 2011) ${ }^{6}$.

Respostas estão sendo construídas e foram debatidas na Jornada. Dois pontos centrais nelas são destacados nesse editorial porque são eles que estão perpassando todos os textos dessa edição, quais sejam: a categoria da determinação econômica e a necessidade da luta ideológica. Os textos ora apresentados versam diretamente sobre essa luta e, de modo mediado, versam sobre a categoria determinação.

Isabel Monal em sua fala destaca que "en una rede de múltiples factores hay uno que da la condición en última instancia, o sea, hay uno que tiene la capacidad de la determinación", referindo-se ao modo de produção e reprodução da vida ou, em termos comum, a economia. Marx ${ }^{7}$ (2011) evidencia a determinação econômica demonstrando que o modo de produção não produz apenas o produto para o consumo, mas, também, o sujeito apto a consumi-lo e os órgãos necessários à mediação entre produção, circulação e consumo, tendo em vista que, sob a divisão social do trabalho no sistema do capital, o indivíduo produtor direto de mercadorias não é o consumidor imediato delas.

Nesse ínterim, Lebowitz ${ }^{8}$ (2011, p. 49) destaca as seguintes palavras de Marx: "En el transcurso de la produción capitalista se va formando una clase obrera que, a fuerza de educación, de tradición, de costumbre, se somete a las exigencias de este régimen de producción como a las más lógicas leyes naturales". Sustentado por essas palavras de Marx, o autor (2011, p. 58) adverte: "[...] una lucha ideológica no puede librarse exitosamiente po sí sola. Sin la creación [... d]el espacio

\footnotetext{
${ }^{4}$ Destaco a fala de Gilberto Valdéz: "Ese país no es un país socialista, per un país que está en transición". Sua fala destaca a necessidade de superar a visão etapista da história de correntes de uma compreensão equivocada dos escritos de Marx, assim como reivindicado por Michael Lebowitz no texto Construyendo el socialimos para el siglo XXI: la lógica del Estado. In: Revista Internacional Marx Ahora. La Habana, Cuba: n³1, 2011, p. 48-65.

${ }^{5}$ MÉSZÁROS, I. Para além do capital. São Paulo: Boitempo, 2006.

${ }^{6}$ LUKÁCS, G. Prolegômenos Para uma Ontologia do Ser Social. São Paulo: Boitempo, 2010.

${ }^{7}$ MARX, K. Grundrisse: Manuscritos econômicos 1857-1858: esboço da crítica da economia política. São Paulo: Boitempo; Rio de Janeiro: Edu UFRJ, 2011.

${ }^{8}$ LEBOWITZ, M. Construyendo el socialimos para el siglo XXI: la lógica del Estado. In: Revista Internacional Marx Ahora. La Habana, Cuba: n³1, 2011, p. 48-65.
} 


\section{EDITORIAL - PENSAMENTO MARXIANO: BREVES PALAVRAS SOBRE LUTA IDEOLÓGICA, DETERMINAÇÃO ECONÔMICA E AMÉRICA LATINA

necesario al desarrollo humano por medio de la práctica, la batalla de ideas carecería de una base real para el desarrollo ("tanto individual como colectivo ${ }^{9 ")}$ ".

Tendo em mente essas colocações e a discussão da Jornada sobre luta ideológica e a categoria da determinação, as considerações dos textos presentes nessa edição da RBEO são complementares entre si e entre as discussões de outros intelectuais latino-americanos. Quanto aos textos dessa edição, ainda que haja, em alguns momentos, diferentes interpretações realizadas pelos autores, há unidade epistemológica, permitindo o exercício de um diálogo construtivo para o leitor e, quiçá, o avanço na construção do conhecimento.

O texto de Arbia, por exemplo, nos traz a possibilidade de pensar de forma imediata a categoria da determinação econômica, ao destacar os "elementos sintéticos para uma compreensão da crise estrutural do capital". Por sua vez, o texto de Rodrigo Martoni, ao trazer o debate sobre a ideologia e o uso do e no espaço turístico, lança luz sobre a operação da luta ideológica e sua necessária correspondência com a prática. O mesmo é possível dizer sobre o texto de Araújo, que, embora não discuta diretamente a categoria ideologia, demonstra os elementos práticos impostos à profissionalização docente no Brasil e, por desdobramento, a ideologia que se constitui hegemônica.

Práticas efetuadas no campo educacional que não estão descoladas, de forma alguma, do movimento geral de expansão do Capital, como demonstra o texto de Valéria Martoni ao discutir o Reuni e as diretrizes para a educação do Banco Mundial. Diretrizes condizentes com a necessidade do capital de formar uma classe trabalhadora que, "por força da educação" se submete ao regime do capital como se lei natural fosse.

Submissão, sim, todavia, não sem resistências! -- ainda que, nem sempre com a mesma intensidade de força - como demonstra o texto de Calvacante, Guedes e Campos. Os autores trazem o exemplo do movimento estudantil para problematizar seus avanços e recuos, bem como destacar como a luta ideológica, para avançar rumo à emancipação humana, necessita discutir as opressões sociais a partir de uma perspectiva de classe. (Essa articulação, destaco, é necessária para que não nos percamos no culturalismo -- marxista ou não -- que reproduzem relações alienadas. Tema também discutido na jornada).

De maneira similar, Justen e Gurgel, ao estudarem as experiências de participação na América Latina, frisam a necessidade de compreensão precisa das categorias participação e cidadania para o avanço da luta de classes. Queiroz, também preocupado com o risco das interpretações que pouco avançam rumo à emancipação humana, destaca em seu textos que a relação entre Administração Política e Guerreiro Ramos tem produzido eufemismos que aparentam mudanças, mas que em nada mudam, reproduzindo, assim o desejo de uma gestão do estado do bem-estar social

${ }_{9}^{9}$ Palavras de Marx em Crítica ao Programa de Gotha. 


\section{EDITORIAL - PENSAMENTO MARXIANO: BREVES PALAVRAS SOBRE LUTA IDEOLÓGICA, DETERMINAÇÃO ECONÔMICA E AMÉRICA LATINA \\ Deise Luiza Ferraz}

sob o capital - como se isso ainda fosse possível -, mas que, por mais que "distribua a riqueza" não liberta o trabalho, pois o problema do Capital não está na distribuição, mas na produção, como já destacou Marx: de cada modo de produção desdobram-se modos de distribuição que lhe cabe.

Em suma, ao se discutir, seja o Brasil ou a América Latina, as questões problematizadas na Jornada - luta ideológica e determinação econômica estão presentes. O movimento de expansão do capital, conforme especificidades dos distintos países da América Latina, ao invés de ser uma força que, "ao provocar mudanças em Cuba, apaga a última vela de esperança para os que sonham e lutam por uma sociedade verdadeiramente humana", segundo depoimento de um participante da Jornada, nos demonstra a necessidade de reforçarmos o retorno ao Marx. Retorno que nos permite entender a inevitabilidade desse avanço da expansão em Cuba e a ofensiva na esfera política para o avanço na expansão na esfera econômica vivenciada em Brasil, Venezuela, Argentina, etc. Compreensão que remete à necessidade histórica que se coloca a todas e a todos os trabalhadores nesse momento de recrudescimento da luta ideológica, política e ética, de converterem-se em sujeitos históricos.

Diga-se, para concluir, que essa edição da $\mathrm{RBEO}^{10}$, portanto, está em consonância com o movimento geral das ideias. Um retorno a Marx está sendo realizado em todos os continentes, isso porque, em todos, o capital recrudesceu sua ofensiva, afinal, o movimento das ideias se dá a partir de um solo concreto.

Que esses textos fomentem a reflexão crítica do que se passa em solo pátrio. Que o passo dado pela Sociedade fomente um olhar atento para a América Latina e o Caribe. Que a leitura dessa edição seja a centelha que faltava.

Habana, 14 de dezembro de 2015.

10 Em nota final, mas não menos importante, agradeço publicamente a Cintia Rodrigues de O. Medeiros, pelo apoio dado na realização desta edição. Embora ela não tenha nenhuma responsabilidade pelas palavras deste editorial e dos textos seguintes, sem o trabalho dela, dificilmente terminaríamos em tempo esta edição. 